\title{
Solitary Bone Cysts Developed in Two Different Bones of a Patient with An Interval of 9 Years
}

\author{
Kircho Patrikov* \\ Department of Orthopedics and Traumatology, Bulgaria \\ *Corresponding author: Kircho Patrikov, Department of Orthopedics and Traumatology, University Hospital of \\ Orthopedics-Sofia, Bulgaria
}

\begin{tabular}{|c|}
\hline ARTICLE INFO \\
\hline Received: 觜 December 28, 2020 \\
\hline Published: 豐 January 08, 2021 \\
\hline
\end{tabular}

Citation: Kircho Patrikov. Solitary Bone Cysts Developed in Two Different Bones of a Patient with An Interval Of 9 Years. Biomed J Sci \& Tech Res 33(1)-2021. BJSTR. MS.ID.005344.

\begin{abstract}
Summary

Simple bone cyst (synonym - solitary bone cyst (SBC), unicameral bone cyst (UBC) is included by the WHO, 2013, in the group of tumors of indeterminate neoplastic nature, in the subgroup of benign tumors [1-3]. It is single-chambered, located centrally in the bone. The neoplasm is expansive, osteolytic, without periosteal reaction, with the exception of tumors complicated by the common pathological cyst fracture (70\%).

Material and Methods: We present a unique case in our practice - the appearance of simple bone in two different bones of the same patient, with an interval between the two 9 years. A 15-year-old patient with a cyst in the left humerus, treated surgically, and after a later fracture - conservatively. The fracture and cyst are healed, the function of the joint is completely restored. Nine years later, the same patient was diagnosed with a cyst in the left clavicle. Both lesions were histologically proven. So far in the literature we have not found such a case described.
\end{abstract}

Results: Minimal bone resection for biopsy and subsequent immobilization for 30 days was sufficient to cure the clavicle cyst.

\section{Introduction}

Simple bone cyst occurs in children and adolescents with a peak between 3 and 14 years, with a mean age at diagnosis of 9 years [1,2,4-7]. Approximately $70 \%$ of patients are between 4 and 10 years of age. This bone lesion accounts for about $3 \%$ of all biopsied bone tumors. It is known to affect only one bone in the skeleton. Simple bone cysts are diagnosed in almost every bone. However, more than $95 \%$ of cases are related to long bones [4]. The proximal parts of the humerus and femur account for almost $70 \%$ of these cases.

\section{Material and Methods}

We report a unique case - the appearance of a simple bone cyst in two different bones of the same patient, with an interval between the two lesions of 9 years. A 15-year-old boy with complaints of pain in his left arm for 3 months. On radiography, a simple bone cyst in the proximal humerus was diagnosed Figure 1a. In our clinic, surgical treatment was performed by bone resection, cyst drainage and filling of the bone cavity with calcium phosphate Figure 1b. Histological examination showed a simple bone cyst. Thirty months after the operation, in case of trauma, the patient received a fracture of the operated bone and radiography revealed complete resorption of the graft Figure 1d. Conservative treatment was performed by immobilization, which led to complete healing of the bone and healing of the cyst Figure $1 \mathrm{e}$. 

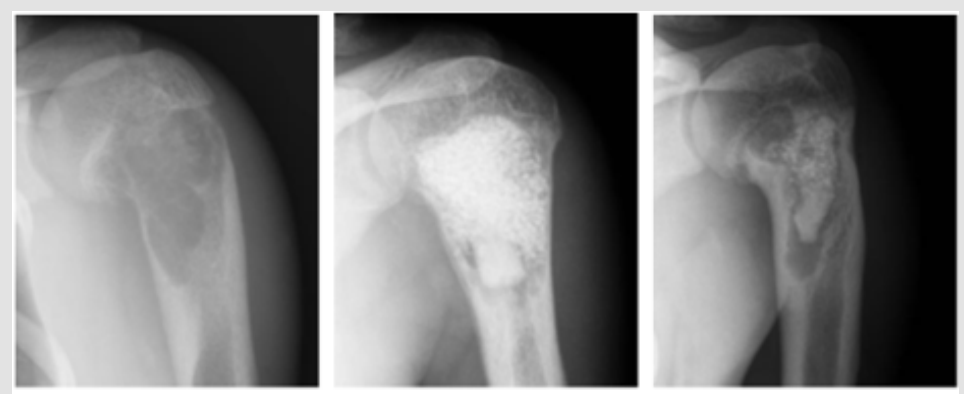

a
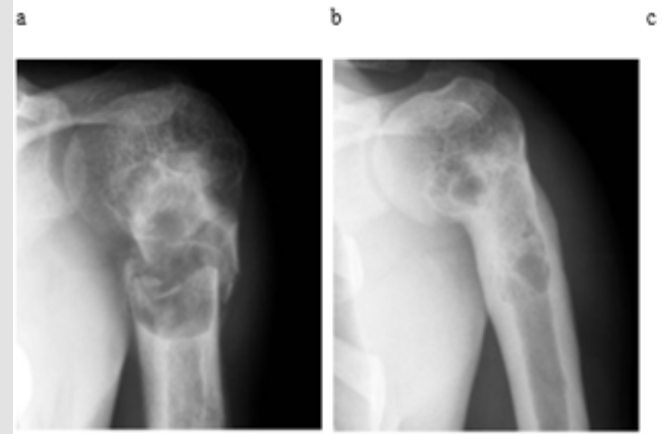

d

e

Figure 1: Cyst in the humerus of a 15-year-old

a) Peripheral resorption of the graft 3 months. postoperatively

b) which progressed 9 months. after surgery

c) Bone fracture 30 months postoperatively with complete resorption of the graft

d) After conservative treatment, fracture consolidation and function in the shoulder joint occurred $100 \%$ according to MSTS (e).

\section{Results}

The upper limb was immobilized with an orthosis for 30 days and 2 months later no complaints were found and the shoulder joint was fully functional. Figure 2 Bone resection and cyst drainage proved to be sufficient for osteogenesis, which led to bone repair and cyst healing.

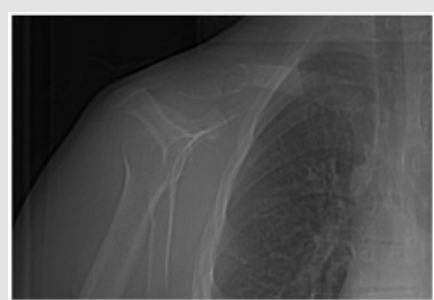

a

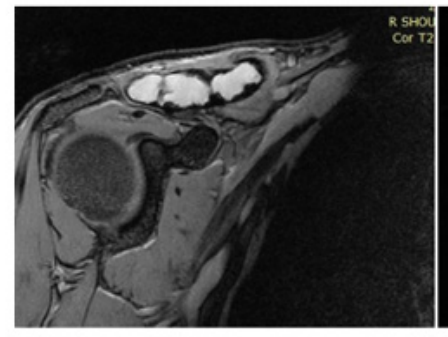

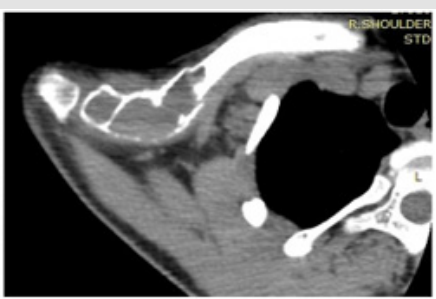

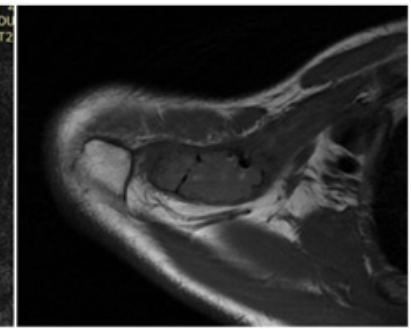

Figure 2: Nine years later, the same patient was admitted to the clinic with complaints of pain in the right shoulder and on radiography, CT and MRI diagnosed a lesion in the lateral part of the right clavicle, complicated by a pathological fracture (Figure $2 \mathrm{a}, 2 \mathrm{~b}, 2 \mathrm{c}$ ). We performed a biopsy that showed a simple bone cyst. 


\section{Discussion}

The solitary bone cyst begins in childhood and adolescence, which is the period of greatest activity in bone growth. If intact, the solitary bone cyst is represented by a single cystic compartment, i. it is single-chambered, hence its name and is located centrally in the bone. It usually develops in only one bone of the human skeleton. The goal of treatment is to prevent or treat an already existing pathological fracture, to stimulate the healing of the cyst, to prevent recurrence and recurrence of the fracture. The surgical approach should be considered for those patients who have a threatening or already established pathological fracture. Also, in those whose cysts continue to enlarge, or cysts located in the supporting bones with a high risk of pathological fracture, such as the proximal femur $(102,128)$.

\section{Conclusion}

In this report, we point out that, although single, a simple bone cyst may develop in another skeletal bone of the same patient. In such cases, it is appropriate to prove the diagnosis by biopsy. The therapeutic plan is individualized for each patient, based on clinical and radiological features.

\section{References}

1. Biermann JS (2002) Common benign lesions of bone in children and adolescents. J Pediatr Orthop 22(2): 268-273.

2. Boseker E, Bickel W, Dahlin DA (1968) clinicopathologic study of simple unicameral bone cysts. Surg. Gynecol. Obstet 127(3): 550-560.

3. Kalil RK, E Santini Araujo (2013) Simple bone cyst. In: WHO, Classification of Tumours of Soft Tissue and Bone, 4th Edition. Ed Ch Fletcher, JA Bridge, P C W Hogendoorn, F. Mertenu. Lyon, IARC 350-351.

4. Lokiec F, Wientroub S (1998) Simple bone cyst: etiology, classification, pathology, and treatment modalities. J Pediatr. Orthop B 7(4): 262-273.

5. Pretell-Mazzini J, Murphy RF, Kushare I, Dormans JP (2014) Unicameral bone cysts: general characteristics and management controversies. J Am Acad Orthop Surg 22(5): 295-303.

6. Shahryar Noordin, Salim Allana, Masood Umer Mujahid Jamil, Kiran Hilal, Nasir Uddin, et al. (2018) Unicameral bone cysts: Current concepts 34: 43-49.

7. Wilkins RM (2000) Unicameral bone cysts. J Am Acad Orthop Surg 8(4): 217-224.

$\begin{array}{ll}\text { BIOMEDICAL } & \text { Assets of Publishing with us } \\ \text { RESEARCHES } & \text { - Global archiving of articles } \\ \text { - Immediate, unrestricted online access } & \text { - Rigorous Peer Review Process } \\ & \text { - Authors Retain Copyrights }\end{array}$

